\title{
Muscle Tenderness, Other Carcass Traits and the Effect of Crossbreeding on These Traits in Beef Cattle
}

\author{
W.D. Slanger, M.J. Marchello and R.B. Danielson
}

Cundiff (1985) states: "It is estimated that today about 70 percent of the calves marketed from beef cattle breeds in the United States are crossbred and that between 50 and 60 percent of the cows are crossbred. This represents a major shift to crossbreeding from straightbreeding which prevailed into the late $1960^{\prime}$ s in response to research demonstrating favorable effects of heterosis (e.g. see review by Cundiff, 1970." Research results have continued to affirm this trend of increased crossbreeding. For instance, research has shown that a three-breed crossbreeding program can increase production in terms of pounds of calf weaned per cow exposed to breeding by 23 percent (Cundiff et al., 1974). Cundiff (1984) provided further information on the productivity of $F_{1}$ cows.

Clearly, this trend of increased marketing of finished crossbred cattle would not have continued if crossbreeding resulted in obvious detriments to the tenderness of the cooked meat or to other important carcass traits. However, objective information on the effect of crossbreeding on tenderness and other carcass traits was needed to assess the inmediate and long-term ramifications of suppying meat from crossbred cattle to consumers. If sexing of bull semen becomes possible, it will be important to know if steers and heifers are different with regard to carcass traits. Also of interest is the extent of the differences, if any, among different cooked muscles. Therefore the objectives of this study were to: 1) measure differences of tenderness among muscles, 2) assess the differences between steer and heifers for various carcass characteristics, and 3) to estimate the effect that crossbreeding has on carcass traits (Slanger et al., 1985).

\section{Experimental Procedure}

Carcass information was accumulated for eight years (1971 through 1978) on approximately 475 steer and 125 heifer carcasses representing eight breeds and 62 combinations of these eight breeds. All these cattle were raised, finished and slaughtered at North Dakota State University. The eight breeds were Angus, Hereford, Shorthorn, Charolais, Brown Swiss, Simmental, Galloway and Red Angus. The data were from straightbred, two-, three- and four-way crossbred cattle. However, straightbreds, $F_{1}$ 's

Slanger and Danielson are associate professors and Marchello is professor, Department of Animal and Range Sciences. and progeny from backcrosses made up the majority of the combinations. The animals were all born in the spring, weaned at approximately 185 days, and entered the feedlot two to three weeks after weaning. There were steers and heifers represented each year and the two sexes were managed similarly. The same ration was fed to all cattle. It was a complete 12.5 percent protein mixture containing 12.5 percent alfalfa, 84 percent grain mixture of barley, oats and corn and fortified with a 3.6 percent commercial mineral-vitamin supplement. Cattle were fed until they reached weights of approximately 1050 pounds. Animals were then slaughtered commercially and aged in a 34 to $37^{\circ} \mathrm{F}$ cooler for 10 days prior to processing.

Steaks cut $1 \frac{1}{4}$ inches thick were removed from three areas of the carcass: the shortloin, sirloin and bottom round. The loin eye muscle $(\mathrm{N}=627)$ was removed from the anterior end of the shortloin. A top sirloin steak ( $N=611$ was cut from the center portion of the sirloin. An eye of the round steak $(\mathrm{N}=634)$ was removed 3 inches posterior to the rump. Samples were individually wrapped in laminated freezer paper, quick frozen and stored at $0^{\circ} \mathrm{F}$. Individual steaks were then thawed to an internal temperature of $35^{\circ} \mathrm{F}$ and cooked in a deepfat-fryer at $381^{\circ} \mathrm{F}$. Each steak was cooked approximately 20 minutes to an internal temperature of $160^{\circ} \mathrm{F}$. Steaks were allowed to cool 30 minutes prior to measurement of tenderness by the Warner-Bratzler Shear machine. After removal from the deepfat-fryer, the temperature of the steaks continued to rise because of the influence of cooking on fat, protein and moisture. The highest temperature the meat sample reached after cooking was recorded. The Warner-Bratzler machine records the pounds of force required to shear through a 1-inch core of cooked fibers at right angles to the long axis.

Other measurements taken on the carcasses were fat cover $(\mathrm{FC})$, percent kidney fat (PK), carcass weight (CW), loin eye area (LEA), yield grade (YG), quality grade (QG) and marbling (MB). Yield grade is the percent of the closely trimmed retail cuts from the rump and round, loin, rib and chuck expressed as a numerical value of 1 to 5 with 1 being the most desirable and 5 being the least desirable. Quality grade is an estimation of the palatability or eating characteristics of steaks or roasts with regard to flavor, juiciness and tenderness. There are eight quality grades: prime, choice, good, standard, commercial, utility, cutter and canner. Meat purchased over the counter is of the choice and good grades. Theses are represented by the 
numbers 12 through 7 , with 12 being the most desirable. Quality grade is determined by two factors: maturity or the age of the animal as observed by the ossification of the bone and by marbling. Marbling is the intermingling of fat within the muscle as seen in the cut lean surface of the loin eye muscle at the 12 th rib interface. Various degrees of marbling represent different grades and can be expressed numerically with numbers 1 through 10 .

\section{Results and Discussion}

There was a clear difference in the tenderness of the muscles studied. The loin eye was the most tender followed by the top sirloin. The eye of the round was the least tender. Figure 1 shows that it required 2 and 0.87 fewer pounds of force, respectively, for the loin eye muscle and top sirloin muscle to be sheared than did the eye of the round muscle. These differences were highly significant from a statistical point of view. (Note: Results that were statistically significantly to the extent of warranting one or more of the conclusions given in the conclusions section are indicated in the figures by solid lines and the inclusion of the statistical significance levels (P's). Statistically nonsignificant results are shown with dotted lines and, while generally accurate, cannot be interpreted with the same confidence as the statistically significant results. It is helpful to keep in mind when interpreting the figures that statistical significance sometimes did not result for the heifer estimates because of the considerably smaller number of heifer carcasses. It is also important to keep in mind that the scale of the graph used to show the results is almost always different for each trait, i.e., visual comparison of one trait to another is not possible except for traits shown in figure 1 and 3.)

For all three muscles, higher post-cooking temperatures tended to be associated with greater tenderness. This may

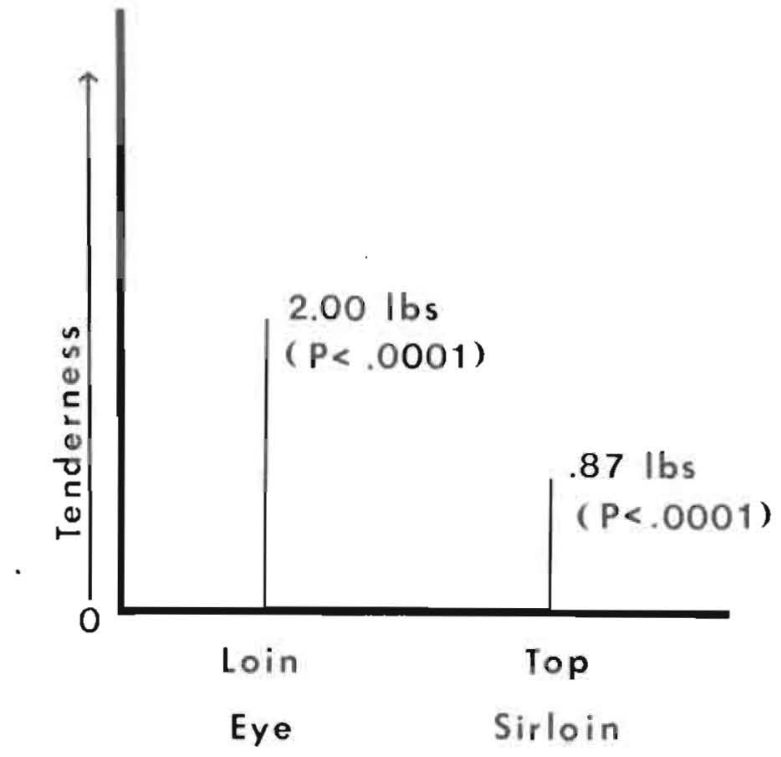

Figure 1. Number of pounds more tender cooked loin eye and top sirloin muscles were than the eye of the round.

have been because the steaks were cooked in an oil bath (conduction) rather than broiled (convection). The correlations between measurements of tenderness of the three muscles were highly statistically significant $(P .0001)$ and positive but were not high (.3 to .4$)$.

Figure 2 shows the differences between steers and heifers for the 10 carcass traits. Steer muscles were more tender
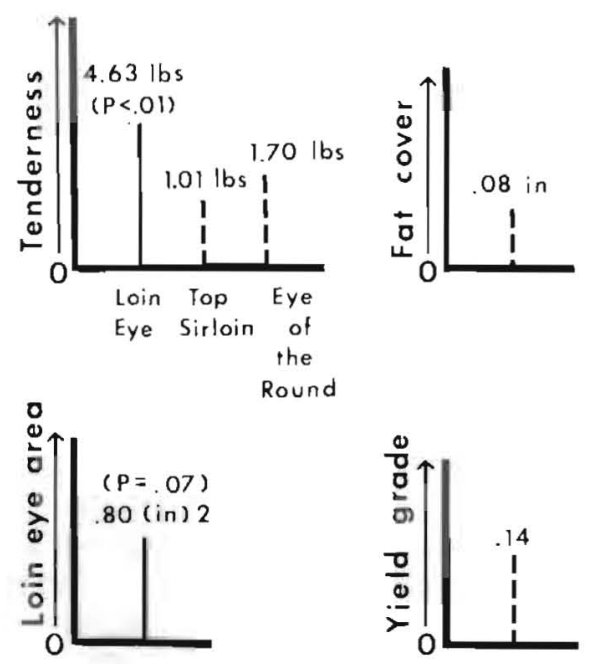
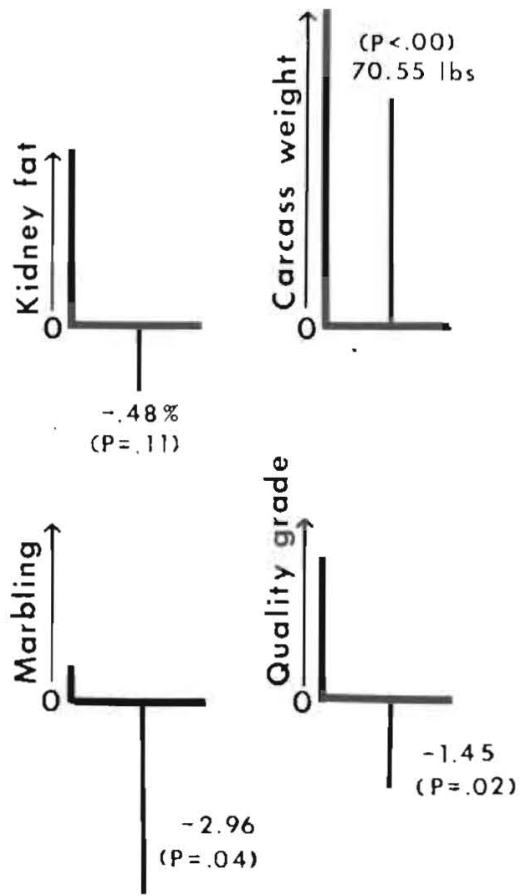

2.96
$=.04)$

Figure 2. Differences between steers and heifers (heifer values were subtracted from steer values) for tenderness of three cooked muscles and seven carcass characteristics. 
than those of heifers. This was particularly evident for the loin eye. Steer loin eyes required 4.6 pounds less force to shear than heifer loin eyes. Steers had nearly .1 inch more fat cover, .5 percent less kidney fat, .8 square inches larger loin eye area and 71 pounds heavier carcasses. The average yield grade was 2.6. Heifers, on the other hand, had an average yield grade of 2.5 , so in essence the carcasses were similar in percentage lean meat. Heifers consistently possessed a greater degree of marbling. This resulted in a quality grade of low choice on the average while steers, because of lower average marbling score, graded high good. This is significant from the producer standpoint because the market price spread between choice and good grade cattle will normally range from $\$ 2$ to $\$ 8$ per cwt. Traditionally packers pay $\$ 2 / \mathrm{cwt}$ less for heifers. The increased marbling in the heifers would offset a $\$ 2.00$ differential.

Figure 3 shows the effect increased percent crossbreeding has on the tenderness values of loin eye, top sirloin and eye of the round. The slopes of the lines show whether the data indicated that the trait would increase or
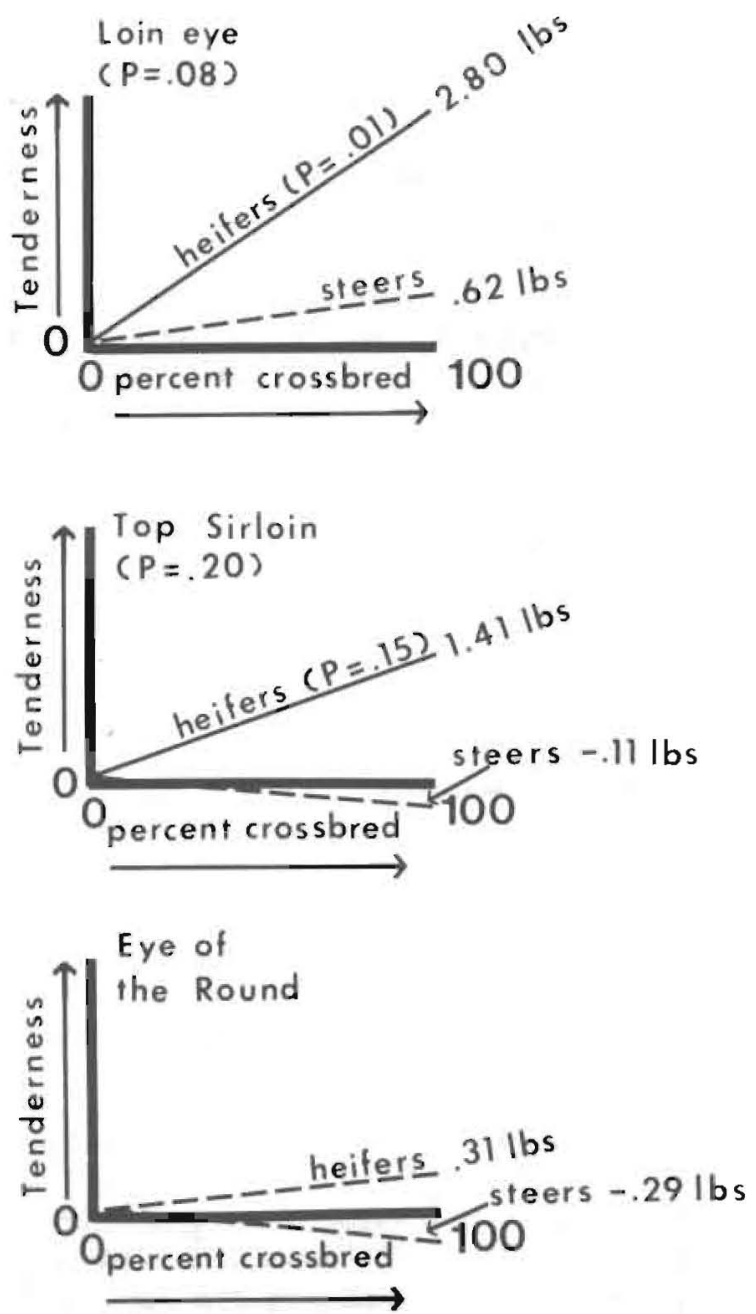

Figure 3. Effects of increased percent crossbreeding (from $0 \%$ to $100 \%$ ) on the tendemess of three cooked muscles in steers and heifers. decrease with increased percent crossbreeding. The numbers at the ends of lines show how much more or less a 100 percent crossbred animal is expected to differ from a straightbred animal. A 100 percent crossbred animal would result from the mating of two straightbreds of different breeds, say Angus and Hereford. A 50 percent crossbred animal would result from mating a 100 percent crossbred with a straightbred of either of the two breeds making up the 100 percent crossbred, say an AngusHereford cow mated to an Angus bull. Many percentages between 0 and 100 are possible. The important conclusion is that crossbreeding does not reduce the tenderness of the cooked muscles, but probably increases the tenderness, at least somewhat. The increase was striking for heifer loin eye and impressive also for heifer top sirloin. The eye of the round results also supported the conclusion that tenderness increases with increased percent crossbreeding more so in heifers than steers. If the differences in the slopes and the lines of the graphs presented in figures 3 to 5 were statistically significant, the $P$ value is given in the upper-left comer.

Figure 4 shows the effects of crossbreeding on the traits of FC, PK, CW and LEA. Fat cover increases at the same rate for steers as for heifers. There was a striking difference between steers and heifers for PK, CW and LEA. Percent kidney fat decreased in heifers at twice the rate PK increased with steers. Carcass weight increased considerably for heifers but stayed about the same for steers. Increased crossbreeding made heifer LEA larger but had no effect on steer LEA.

Figure 5 shows the analogous graphs for YG, QG and $M B$. The results were very nonsignificant from a statistical point of view and the conclusion is that crossbreeding does not affect these traits.

\section{Conclusions}

There were definite differences among loin eye, top sirloin and eye of the round for tenderness, with loin eye much more tender than top sirloin and top sirloin more tender than eye of the round. Carcasses that were tender for one of the three muscles tended to also be tender for the other two, but this relationship was not particularly strong.

Steer muscles were more tender than those of heifers, and particularly so for loin eye. Besides the obvious difference in carcass weight, steers had less percent kidney fat, larger loin eye area, less marbling and lower quality grade.

Crossbreeding did not have an adverse effect on muscle tenderness. Muscle tenderness increased in heifers with increased percent of crossbreeding. Fat cover increased as percent crossbreeding increased. The effect increased crossbreeding had on percent kidney fat, carcass weight and loin eye area was different for heifers than for steers, with percent kidney fat decreasing for heifers and increasing for steers and carcass weight and loin eye area increasing for heifers. Yield grade, quality grade and marbling did not change with increased percent crossbreeding. 


\section{References}
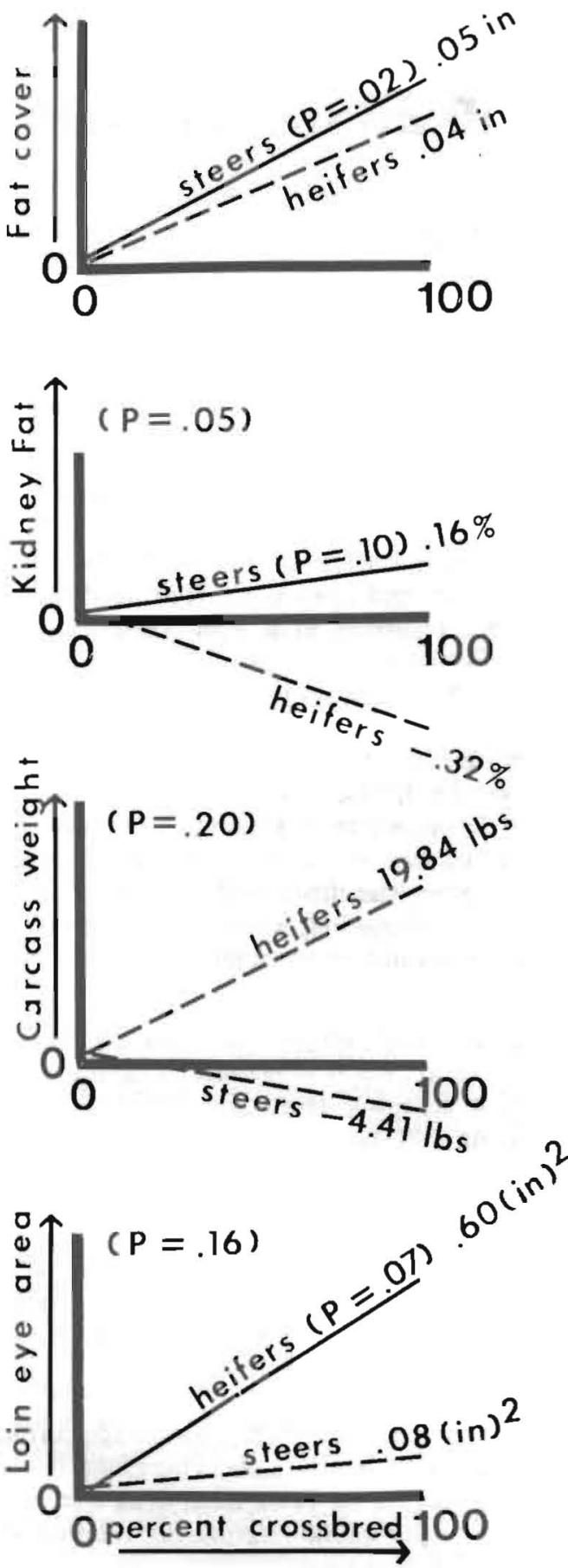

Figure 4. Effects of increased percent crossbreeding (from $0 \%$ to $100 \%$ ) on four carcass characteristics in steers and heifers.
Cundiff, L.V. 1970. Experimental results on crossbreeding cattle for beef production. J. Anim. Sci. 30:694.

Cundiff, L.V., K.E. Gregory and R.M. Koch. 1974. Effects of heterosis on reproduction in Hereford, Angus and Shorthorn cattle. J. Anim. Sci. 38:711.

Cundiff, L.V. 1984. Output and input differences among diverse breeds of cattle. Proceedings of the 2 nd World Congress on Sheep and Beef Cattle Breeding. Pretoria S. Africa, April 16-19, 1984. Vol. II. Paper No. 52. pp 1-13.

Cundiff, L.V. 1985. Literature review of research project: Germ plasm evaluation in cattle used for beef production.

Slanger, W.D., M.J. Marchello, R.B. Danielson, C.N. Haugse, V.K. Johnson, A.S. Vidal, W.E. Dinusson and P.T. Berg. 1985. Muscle tenderness, other carcass traits and the effect of crossbreeding on these traits in beef cattle. J. Anim. Sci. 61:1402.
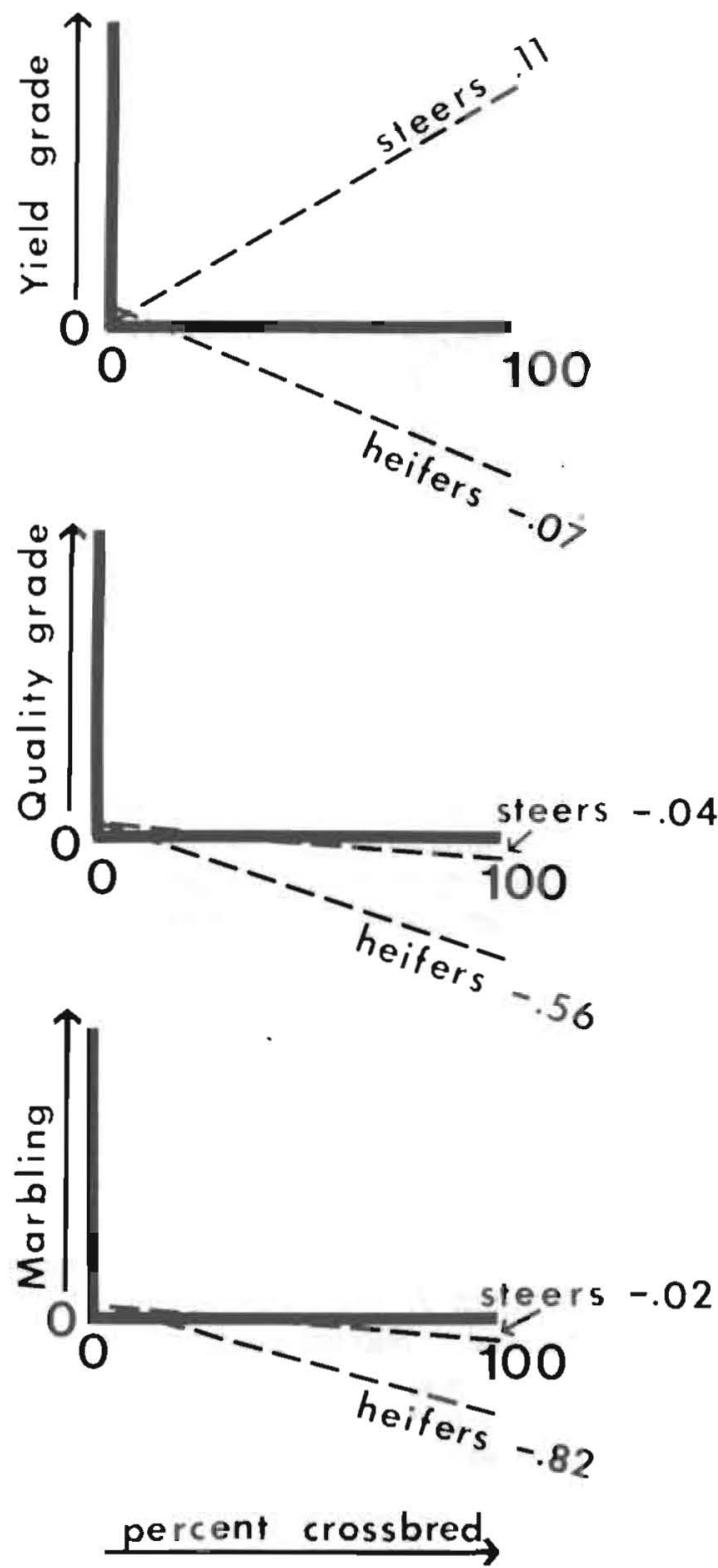

Figure 5. Effects of increased percent crossbreeding (from $0 \%$ to $100 \%$ ) on the carcass characteristics of yield grade, quality grade and marbling in steers and heifers. 